researches on the scale they deserve is, the impecunious institutes of Britain will learn with a shock of sympathy, lack of adequate means.

Put broadly, Dr. Abbot's view rather sounds like pitting against one another the advance of technical knowledge and the scientific education of the people, the latter of which is bound in the end to be more local in its development, since the less educated a person may be the more he must depend on sense impressions and the less on the mental stimulus of the written word; and the Smithsonian plumps heavily for the former. Now we are not convinced that the contrast is a necessary one, since if both the scientific education of the people and the advance of technical scientific knowledge are essential, it can scarcely be said that one is of more value than the other. Both are necessary ingredients in the sum of scientific advancement.

If science is to make the progress it deserves, it must be upon the basis of a wide sympathy and understanding amongst the plain men of the earth. At the lowest terms of this compact, research can obtain the adequate funds which the Smithsonian and every other scientific institution longs for, only when the public has grasped the vital importance of scientific results so thoroughly that it compels the disbursement for such purposes of the State funds which it itself contributes. In other words, in these democratic days, the adequate prosecution of research is inextricably bound up with the scientific education of the people.

\section{Science and Humanism.}

$\mathrm{T}$ HE neglect of science by historians, and the misunderstanding of its service by representatives of labour, are familiar to most readers of Nature. The new review The Realist, to which reference was made in our issue of April 6, p. 540, contains two contributions dealing respectively with these subjects-one by Dr. Singer on scientific humanism and the other by Mr. John Gibson on the relations of labour and science. Both describe from different points of view a state of things which our readers would wish to alter: both resolve themselves ultimately into a question of education.

Dr. Singer starts with the astounding fact, often commented on in these columns, that our accustomed books on history, even such monumental works as the "Cambridge Modern History," ignore, for the most part completely, the rôle played by science in the historic process. As he

$$
\text { No. 3104, VoL. 123] }
$$

says-and it is a new way of putting it-" Had it so fallen out that Galileo and Kepler, Newton and Lavoisier and Darwin had been Persians, Turks, Indians, and Russians instead of Italians, Germans, Frenchmen, and Englishmen, it is very certain that the face of the civilised world would have been quite different from what it is. Yet such names are wellnigh ignored in ordinary works of history." The 'ordinary' historian, when charged with this, says either that history is past politics, or how men have come to live together more or less peacefully in States, or, if he does not subscribe to this narrow and exploded heresy, that he does not know about science and thinks it better to leave it to those who do. The latter argument, however, is not applicable to such a work as the "Cambridge Modern History," which is a composite production and might just as well contain chapters on science as it does certain chapters on literature.

The right solution is one which will take years of philosophic thinking to achieve, namely, what is the place which science has taken in building up the social structure which is, as most of the historians now perceive, the proper subject of history. Dr. Singer therefore seems to us perfectly right in laying more stress on the introduction of science in its proper place in the presentation of general history than on the elaboration of the historic side in the teaching of science, though that also is a good thing.

The article by Mr. Gibson, on science and labour, is more depressing and raises another educational question of a wider kind. Mr. Gibson notes the almost complete absence of any knowledge or interest in science among the workmen whom he has met, and also finds dread and opposition to the spread of machinery as displacing the human worker. $\mathrm{He}$ is probably generalising from the class of workmen - those in the building tradeswho suffer most immediately from the introduction of new machines and have the least turn for mechanics. The picture would not be so black if it were painted of any branch of the engineers. So far as the educational question is concerned, it should be easier rather than more difficult to imbue the young workman with some knowledge and interest in science than his more lettered fellow-scholar who gives so much time to literature and the study of the dead languages. The boy who goes to a technical or a central school with an industrial bias-and these places are growinghas a good opportunity of approaching science at least on the practical side, and Mr. Gibson's account of the young man of to-day who does all 
the needed repairs to his motor bicycle or his wireless set, inspires one with some hope. It is, of course, precisely by that channel that the intelligent teacher of science will approach the theoretical basis.

On the question of the displacement of the man by the machine, Mr. Gibson is dealing with a problem of social and economic organisation which has been with us all through the Industrial Revolu. tion. It cannot be said that we have dealt with it very wisely or successfully, and yet we are all agreed that operations which can be as efficiently performed by a machine should, in the interest alike of production and the producer, be so done. Every displacement, however, should be accom. panied by careful provision for the displaced. The social raison d'etre of the machine is that it frees the human agent for other work, either in the further conquest of Nature or the development of his own faculties.

\section{Srinivasa Ramanujan.}

Collected Papers of Srinivasa Ramanujan. Edited by G. H. Hardy, P. V. Seshu Aiyar and B. M. Wilson. Pp. xxxvi +355. (Cambridge: At the University Press, 1927.) 30s. net.

$\mathbf{R}^{\mathrm{A}}$ AMANUJAN was born in India in December 1887, came to Trinity College, Cambridge, in April 1914, was ill from May 1917 onwards, returned to India in February 1919, and died in April 1920. He was a fellow of Trinity and a fellow of the Royal Society.

Ramanujan had no university education, and worked unaided in India until he was twenty-seven years of age. When he was sixteen he came by chance upon a copy of Carr's "Synopsis of Mathematics", and this book, now sure of an immortality its author can scarcely have dreamt of, woke him quite suddenly to full activity. A study of its contents is indispensable to any considered verdict upon Ramanujan. It gives a very full account of the purely formal side of the integral calculus, containing, for example, Parseval's formula, Fourier's repeated integral, and other 'inversion formulæ'. There is also a section on the transformation of power series into continued fractions. Ramanujan somehow acquired also an effectively complete knowledge of the formal side of the theory of elliptic functions (not in Carr). The matter is obscure, but this, together with what is to be found in, say, Chrystal's "Algebra", seems to have been his complete equipment in analysis and theory of numbers. It is at least certain that he knew nothing of operations with divergent series or of work on the distribution of primes. Above all, he was totally ignorant of Cauchy's theorem and complex function-theory.

The work he published during his Indian period did not represent his best ideas, which he was probably unable to expound to the satisfaction of editors. In the beginning of 1914, however, a letter from Ramanujan to $\mathrm{Mr}$. Hardy (then at Trinity, Cambridge) gave unmistakable evidence of his powers, and he was brought to Trinity, where he had three years of health and activity.

I do not propose to discuss here in detail the work for which Ramanujan is solely responsible (a very interesting estimate is given by Prof. Hardy, p. xxxiv). If we leave out of account for the moment a famous paper written in collaboration with Hardy, his definite contributions to mathematics, substantial and original as they are, must, I think, take second place in general interest to the romance of his life and mathematical career, his unusual psychology, and, above all, to the fascinating problem of how great a mathematician he might have become in more fortunate circumstances. In saying this, of course, I am adopting the highest possible standard, but no other is appropriate.

Ramanujan's great gift is a 'formal' one; he dealt in 'formulæ'. As a specimen we may take the following (which no one can ever resist quoting). If $p(n)$ is the number of ways of expressing $n$ as a sum of positive integers ('partitions of $n$ '), then $p(4)+p(9) x+p(14) x^{2}+p(19) x^{3}+\ldots$

$$
=5^{\left\{\left(1-x^{5}\right)\left(1-x^{10}\right)\left(1-x^{15}\right) \cdot \ldots\right\}^{5}} \frac{\}^{6}}{\left\{(1-x)\left(1-x^{2}\right)\left(1-x^{3}\right) \cdot \ldots\right\}^{6}} \text {. }
$$

The great day of formulæ, however, is over. No one, if we are again to take the highest point of view, seems able to discover a radically new type, though Ramanujan comes near it in his work on partition series. A hundred years or so ago his powers would have had ample scope. Discoveries alter the general mathematical atmosphere and have very remote effects, and we are not prone to attach great weight to rediscoveries, however independent they seem. How much are we to allow for this; how great a mathematician might Ramanujan have been 100 or 150 years ago ; what would have happened if he had come into touch with Euler at the right moment? How much does lack of education matter? Was it formulæ or nothing, or did he develop in the direction he did only because of Carr's book-after all, he learned later to do new things well, and at an age mature for an

No. 3104, VoL. 123] 